\title{
Hybrid Effect in In-Plane Loading of Carbon/Glass Fibre Based Inter- and Intraply Hybrid Composites
}

\author{
Ashok Rajpurohit ${ }^{1,2, * \mathbb{C}}$, Sébastien Joannès ${ }^{2, *} \mathbb{E}$, Vicky Singery ${ }^{1}$, Philippe Sanial ${ }^{1}$ and \\ Lucien Laiarinandrasana ${ }^{2}$ (D) \\ 1 Chomarat Textiles Industries, 39 Avenue de Chabannes, 07160 Le Cheylard, France; \\ vicky.singery@chomarat.com (V.S.); philippe.sanial@chomarat.com (P.S.) \\ 2 MINES ParisTech, PSL University, Centre des Matériaux (CMAT), CNRS UMR 7633, \\ BP 8791003 Evry CEDEX, France; lucien.laiarinandrasana@mines-paristech.fr \\ * Correspondence: rajpurohit.ashok@outlook.com (A.R.); sebastien.joannes@mines-paristech.fr (S.J.)
}

Received: 24 November 2019; Accepted: 2 January 2020; Published: 5 January 2020

\begin{abstract}
Experimental studies are presented on quasi-static tensile and compressive loading of composites hybridised at two levels: intraply and interply. Consistent reinforcements in the form of novel unidirectional fabrics were developed using T700SC carbon and E-CR glass fibres. Composites were manufactured using Resin Transfer Moulding process with epoxy resin and characterised to ensure consistency and comparability, further enabling easier understanding and confirmation of hybrid effect in a reliable way. Failure strain in tension for interply hybrid revealed a positive hybrid effect of $+7.4 \%$, while interply hybrid showed a negative hybrid effect of $-6.4 \%$ in compression. Intraply hybrid with three carbon and three glass tows blocked together demonstrated the best mechanical performance among all hybrids; synergistic effects of $+17.8 \%$ and $+39.6 \%$ in tensile and compressive strength, respectively, was observed for this hybrid configuration. The results show that different hybridisation strategies can be exploited to balance cost and performance of composites for structural and lightweight applications.
\end{abstract}

Keywords: hybrid composites; interply/intraply hybrids; resin transfer moulding (RTM); mechanical properties; hybrid effect

\section{Introduction}

Several fibre types and resin systems are available to designers who aim to achieve composite product properties such as high specific strength, high specific stiffness, enhanced energy absorption and reduced cost. In fact, one of the greatest benefits of fibre composites over other materials is their potential for design optimisation. In general, a composite made from a single reinforcing material may not be suitable if it undergoes different loading conditions during its service life and has to satisfy multiple performance conditions. A compromise in one or several properties is rendered essential in such cases. Considering this, hybrid composites with two or more reinforcing fibres can prove to be a better solution for such applications. Fibre hybrid composites are therefore a logical evolution towards even more design freedom and hence more possibility for performance optimisation and cost reduction [1,2]. For these composites depending on the way the fibre constituents are brought together, there exist three configurations: interply hybrids or ply level hybrids, intraply hybrids or tow level hybrids and intermingled hybrids or fibre level hybrids. While interply hybrids have received lot of attention in previous studies, the intraply hybrids, specifically those which are not based on woven fabrics, have been rarely reported.

The failure development in hybrid composites follows similar steps when compared to unidirectional non-hybrid composite, but with a few additional complications. For example, 
for carbon/glass hybrid at a given strain, the glass fibres are less likely to fail than the carbon fibres. This has two consequences: (i) the glass fibres hinder the development of clusters of fibre breaks; and (ii) in a given volume, there are now fewer carbon fibres and this reduces the probability of finding a collection of relatively weak fibres near each other. These aspects contribute to increase the strain at which the low elongation carbon fibres fail. For fibre hybrid composites, "Hybrid effect" is termed as a synergistic effect on the stress-strain response on mechanical loading of hybrids over non-hybrid composite. It is defined in two different ways; one based on apparent increase in the failure strain of the hybrid composite when compared to pure low elongation fibre composite (schematically illustrated in Figure 1a [3]); and the other based on the deviation of mechanical behaviour from the Rule of Mixture predictions (schematically illustrated in Figure 1b) [4,5]. Although the second definition can also be applied to several mechanical properties other than just failure strain, the application of this definition is not straight forward and should be used with great care owing to three reasons: (i) the Rule of Mixtures is not necessarily linear for all properties; (ii) each Rule of Mixtures needs a certain composition parameter and choosing the right one is important [1,6]; and (iii) it does not work for all mechanical properties, for example, Rule of Mixtures cannot be applied for flexural strength. Synergistic effect is also reported for hybrid composites with two or more resin systems [7] or additional constituents such as nano-particles and additives [8,9], but the focus of the current work is on hybrid composites with two or more fibre types.
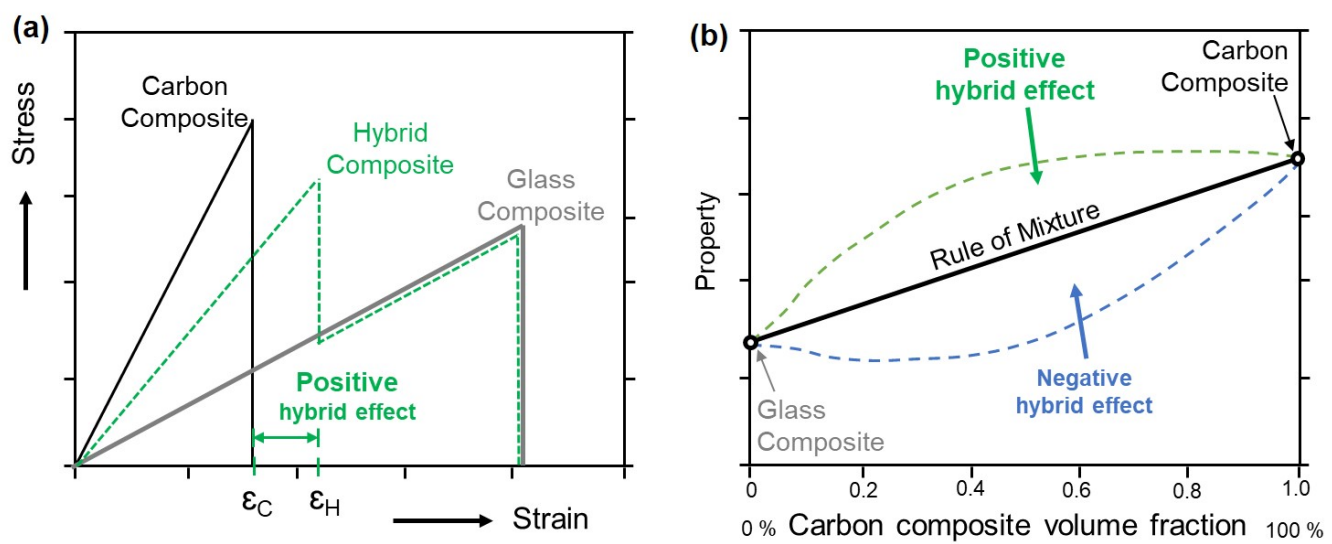

Figure 1. Illustration of the definitions of the hybrid effect or synergistic effect for $C / G$ hybrid composite, based on: (a) apparent enhancement in failure strain; and (b) deviation from Rule of Mixture.

Although both experimental methods and computational models have been attempted since 1970 s to understand the hybrid effect in composites [1,2,10,11], there exist several contradictions and gaps in their reports. Kretsis [1] analysed literature data prior to 1987 and suggested that in earlier studies the hybrid effect observed was influenced by factors such as poor quality carbon material (with lower failure strain) and improper testing and measurements. For recent studies, Swolfs et al. [12] and Wisnom et al. [13] suggested difficulties in measuring the baseline tensile failure strain may be responsible for some of the variability and high values claimed in certain cases for the hybrid effect. In the current work, fabric physical properties, composite fabrication parameters and physical properties were measured and consistently maintained to ensure reliable analysis of hybrid effect.

In terms of computational models, there are several newly developed notable models for hybrids that consider either micro-level events of fibre failure, as reported by Tavares et al. [14] and Guerrero et al. [15], or meso-level ply level failures, as reported by Jalalvand et al. [16]. Few models consider failure at both the levels, such as the one reported by Mesquita et al. [17]. Mesquita et al. [17] and Bunsell et al. [18] reported that the hybrid synergies found in hybrid composites are typically a result from complex interactions of micro-level and meso-level failures. 
For C/G hybrids, three different hypotheses for the hybrid effect have been reported: (i) effect of residual stresses; (ii) changes in the damage development leading to final failure; and (iii) dynamic stress concentrations [2]. Most hypotheses have been applied to unidirectional hybrid composites in interply configuration. These hypotheses can be extended to multidirectional composites as their failure although more complex but still coincides with failure of fibres in the loading direction; however, it is not straightforward.

You et al. [19] reported a hybrid effect of $9 \%$ to $33 \%$ in unidirectional carbon/glass hybrids, while Zhang et al. [20] found improvements in failure strain, ranging between $10 \%$ and $31 \%$ for woven composites. The longitudinal tensile modulus of hybrid composites has been shown to obey a linear RoM, according to many researchers [3-5,10]. Ren et al. [21] reported a higher modulus for intralayer than for interlayer unidirectional carbon/carbon hybrids. The tensile strength for intralayer hybrids was slightly higher than for interlayer hybrids, demonstrating that increased dispersion leads to better mechanical performance in hybrid composites, which was also observed by You et al. [19]. Hwang and Mao [22] studied the compression properties of interlayer hybrid composites, and revealed that an increase in glass fibre content in hybrid composites can decrease the compressive strength. A similar conclusion was confirmed by Yerramalli and Waas [23] who studied a C/G hybrid composite cylinder. According to many authors, the hybrid effect for tensile and compressive strength is based on a bi-linear RoM [1,24] and a positive deviation from the RoM was found and reported in tensile and compression by Pandya et al. [25] and Peijs et al. [26].

Most previous studies focus on the mechanical behaviour and the failure of interply hybrids [25,27], while little work has been conducted on intraply or intermingled hybrid structures [28,29]. In addition, previous studies predominantly report studies on either unidirectional composites or those bi-directional composites made from woven structures [27,30-32]. Considering the overwhelming industrial need for hybrid composites. and that carbon and glass fibres are the most popular reinforcements for usage in structural and semi-structural applications, the current study explored in depth the hybrid configurations and hybrid effects in tensile and compression loading conditions for C/G hybrids made from high strength T700S carbon and E-CR glass fibres. The aim of this study was to develop novel unidirectional hybrid fabrics and their composites with different hybrid configurations, namely interply and intraply, and investigate their mechanical performance in tensile and compressive loading vis-à-vis reference homogeneous non-hybrid composites. Moreover, this study specifically focused on application developments for hybrid composites specifically in the field of sports and leisure products such as skies and wind blade applications such as spar caps $[20,30,33,34]$.

Section 2 addresses the materials, reinforcement and composite fabrication methods and the test procedures to characterise the composite properties. Section 3 discusses the results of mechanical characterisation, failure characteristics and the corresponding "Hybrid effect" in different hybrid configurations. Conclusions are drawn in Section 4 on the failure behaviour of these composites, hybrid effect, and the suitability of developed hybrids for specific lightweight and structural applications.

\section{Experimental Details}

\subsection{Materials}

Toray T700SC carbon and Advantex E-CR glass fibres were selected as the reinforcing fibres for this study. T700SC fibres are high strength fibres manufactured using a PAN precursor. These fibres have excellent processing ability and are widely used in high tensile applications such as pressure vessels and recreational and industrial products. Glass rovings are made with Advantex glass fibres that combine excellent mechanical and electrical properties of traditional E-Glass with the acid corrosion resistance of E-CR Glass. These fibres were used to manufacture glass roving with commercial name 111A Type 30. Carbon $24 \mathrm{~K}$ and glass 1200 tex rovings were commercially procured from Toray Carbon Fibres Europe and Owens Corning respectively. Finer rovings in the form of $12 \mathrm{~K}$ carbon and 600 tex glass were used for reference fabrics to achieve similar C/G ratio in the interply hybrids. A commercial 
epoxy system from Huntsmann Advanced Materials GmbH, Basel, Switzerland, was used and it consisted of Araldite LY 564, a low viscosity epoxy resin, and Aradur 2954, a cycloalophatic polyamine hardener. This system is used in a wide range of applications in industrial composites owing to its suitability for various production processes. The properties of these fibres and cured matrix from their technical data sheets are provided in Table 1.

Table 1. Properties of the constituents at room temperature from technical data sheets.

\begin{tabular}{llccc}
\hline Property & Units & T700S Carbon & E-CR Glass & LY 564 and Aradur 2954 \\
\hline Density & {$\left[\mathrm{g} \mathrm{cm}^{-3}\right]$} & $1.76-1.84$ & 2.62 & 1.1 \\
fibre diameter & {$[\mu \mathrm{mm}]$} & 7 & 17 & - \\
Tensile strength & {$[\mathrm{MPa}]$} & 4510 & 2400 & $71-77$ \\
Tensile modulus & {$[\mathrm{GPa}]$} & $221-240$ & 81 & $2.5-2.6$ \\
Failure strain & {$[\%]$} & 1.9 & 4.9 & $4.5-5.5$ \\
\hline
\end{tabular}

\subsection{Manufacturing Methods}

\subsubsection{Fabric Manufacturing}

Unidirectional reference carbon and glass fabrics along with intraply hybrids were developed using Malimo UD stitching technology. Rovings from the creel were guided through the reed with specific dent spacing suiting the required areal weight. Furthermore, a stabilisation fabric was introduced in the stitching zone, where this uniform stack of reinforcing fibre and the stabilisation fabric were stitched together in a tricot stitching pattern using 170 dtex Polyester threads. The stabilisation fabric used here was a light woven fabric with an areal weight of $42 \mathrm{~g} \mathrm{~m}^{-2}$ made from fine glass yarns, as can be seen in Figure $2 b$. The process parameters along with stabilisation and stitch parameters for all the fabrics were maintained uniformly. The developed fabrics were further quality checked to confirm the compositions of the technical fibre, stitching thread, and stabilisation fabrics. Photographs of the developed fabric reinforcements can be seen in Figure 2a.

(a)

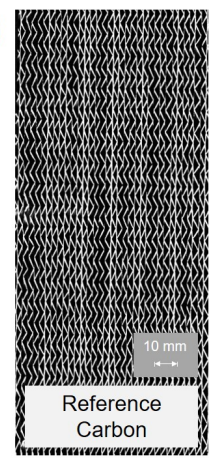

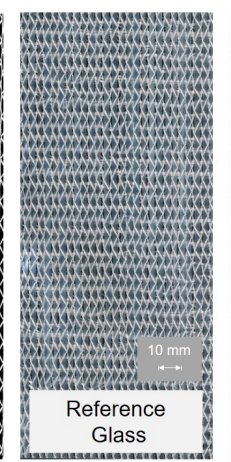

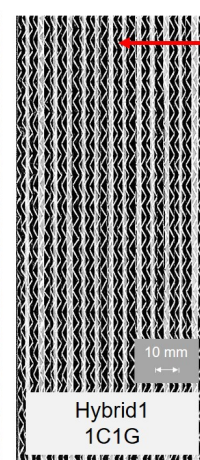

(b)
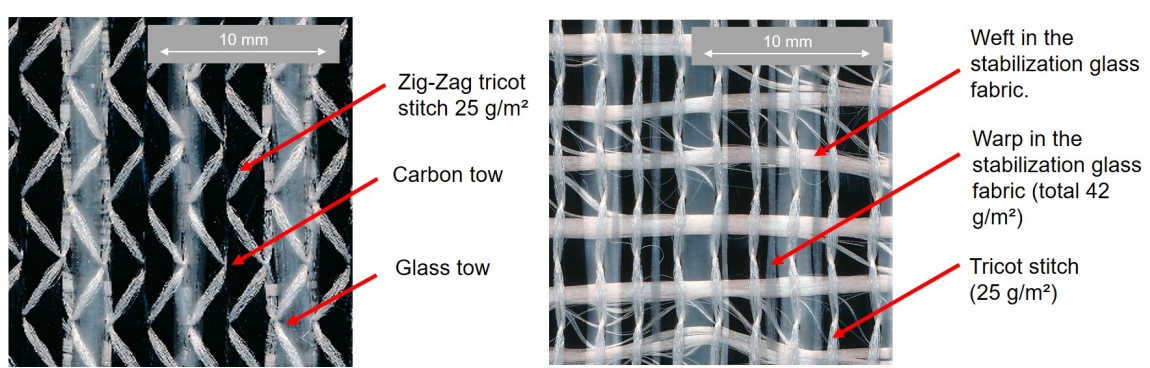

Figure 2. Photographs of developed fabric reinforcements: (a) reference and hybrid fabrics; and (b) magnified images of the face and back of a Hybrid1 fabric. 


\subsubsection{Composite Fabrication}

Composite plates were fabricated using an RTM process equipment from ISOJET Equipments, Corbas, France. RTM is a liquid composite moulding process for polymer matrix composites and is similar to that of liquid infiltration moulding for metal matrix composites [35]. The preforming and RTM parameters were selected considering the infiltration behaviour of the fabrics and that those were kept constant for all the composites fabricated. Preforms were made by laying fabric layers in required orientation sequentially on the aluminium preforming table. A cross-ply, symmetric layup $[0 / 90 / 0]_{S}$ consisting of six layers was used for all except interply hybrid I1 where the layup consisted of 12 alternating glass and carbon layers $\left[0_{\mathrm{G}} / 0_{\mathrm{C}} / 90_{\mathrm{G}} / 90_{\mathrm{C}} / 0_{\mathrm{G}} / 0_{\mathrm{C}}\right]_{\mathrm{S}}$ and had a similar hybrid ratio as the intraply hybrids. After each layer was laid down, a fine layer of epoxy preforming powder (Epikote 05390 from Hexion Inc., Columbus, OH, USA) was applied on the edges coinciding to the final net shape of the preform, as shown in Figure 3a. The stack was then vacuum sealed to $0.3 \mathrm{bar}$ and heated to $80^{\circ} \mathrm{C}$ for $10 \mathrm{~min}$ to activate the binder and consolidate the layers together. After cooling, the preform stack was net shaped to the final mould/part dimensions using roller knife and rested into the cleaned lower mould.

The lower mould $(0.5 \mathrm{~m} \times 0.5 \mathrm{~m})$ contained a line injection channel on one end and three exit ports on the opposite end. On the remaining two sides, a silicon packing was applied in a very fine gap between the preform edge and the mould cavity to avoid "race tracking". The closed mould was then placed into the pneumatic press, which applied a pressure of about 16 bar and heated the mould to a temperature of $60^{\circ} \mathrm{C}$. Vacuum of 0.9 bar was applied to remove the air from the preform and the mould cavity. Pre-mixed and degassed resin was then injected into the mould cavity at 2 bar initially and later the pressure was increased up-to 6 bar. The curing cycle for all composites is schematically presented in Figure 3b. Finally, the composite plate was demoulded after cooling and the edges and the resin channel cut off from the plate. Three sets of composites were manufactured: (i) reference composites, R1 and R2; (ii) intraply hybrid composites, H1, H2 and H3; and (iii) interply hybrid composite I1. The details of manufactured composites and their physical properties along with the fibre Volume Fraction (FVF) are summarised in Table 2.

Table 2. Overview of manufactured composites with mean values of physical properties (standard deviation not reported as it was insignificant for measured properties).

\begin{tabular}{|c|c|c|c|c|c|c|c|}
\hline & $\begin{array}{c}\text { Composite } \\
\text { Name }\end{array}$ & $\begin{array}{c}\text { Fabric } \\
\text { Used }\end{array}$ & $\begin{array}{l}\text { Number } \\
\text { of Layers }\end{array}$ & $\begin{array}{c}\text { Layup } \\
\text { Sequence }\end{array}$ & $\begin{array}{c}\text { Thickness } \\
{[\mathrm{mm}]}\end{array}$ & $\begin{array}{l}\text { Density } \\
{\left[\mathrm{g} \mathrm{cm}^{-3}\right]}\end{array}$ & $\begin{array}{l}\text { FVF } \\
{[\%]}\end{array}$ \\
\hline \multirow[t]{2}{*}{ Reference } & R1 & Ref Carbon & 6 & {$[0 / 90 / 0]_{S}$} & 1.8 & 1.5 & 49.4 \\
\hline & $\mathrm{R} 2$ & Ref Glass & 6 & {$[0 / 90 / 0]_{S}$} & 1.2 & 1.8 & 47.1 \\
\hline \multirow[t]{3}{*}{ Intraply } & H1 & Hybrid1 (1C1G) & 6 & {$[0 / 90 / 0]_{S}$} & 2.6 & 1.6 & 51.3 \\
\hline & $\mathrm{H} 2$ & Hybrid2 (2C2G) & 6 & {$[0 / 90 / 0]_{S}$} & 2.6 & 1.6 & 54.1 \\
\hline & H3 & Hybrid3 (3C3G) & 6 & {$[0 / 90 / 0]_{\mathrm{S}}$} & 2.6 & 1.6 & 51.8 \\
\hline Interply & I1 & Ref Carbon and Ref Glass & $12(6+6)$ & {$\left[0_{\mathrm{G}} / 0_{\mathrm{C}} / 90_{\mathrm{G}} / 90_{\mathrm{C}} / 0_{\mathrm{G}} / 0_{\mathrm{C}}\right]_{\mathrm{S}}$} & 3.1 & 1.6 & 50.4 \\
\hline
\end{tabular}

(a)

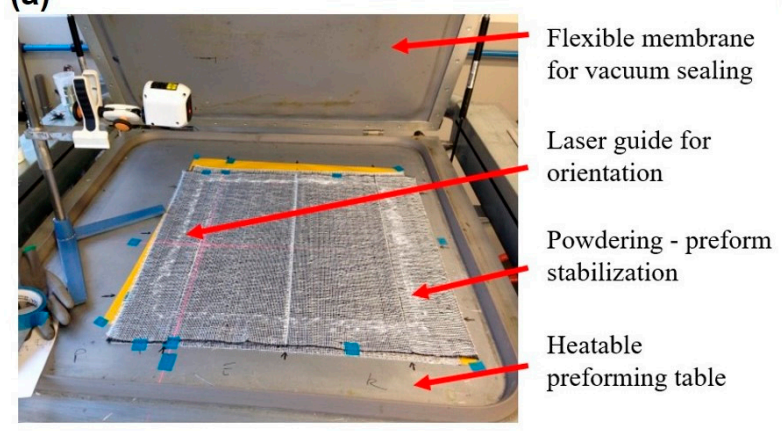

(b)

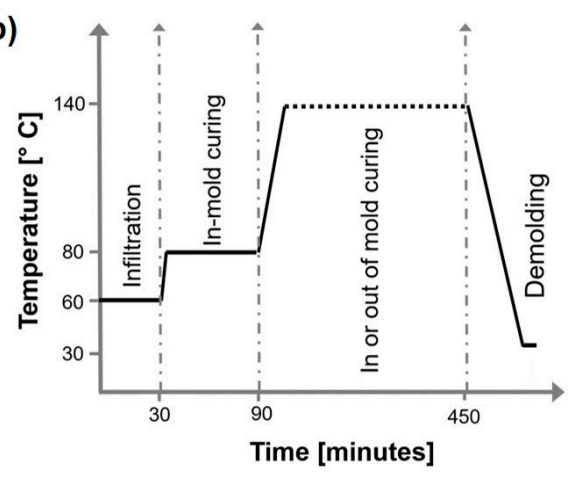

Figure 3. (a) Preforming; and (b) curing cycle for composite manufacturing using RTM. 


\subsection{Material Characterisation}

\subsubsection{Physical Properties, Density and Fibre Volume Fraction}

The physical properties of fabrics were characterised and are presented in Table 3. The fabric parameters showed a very insignificant standard error and the coefficient of variation was recorded to be $<5 \%$. Coverage and the stitching parameters were identified by image analysis of high-resolution scanned pictures of the fabrics. For composites, thickness was measured using micrometer screw gauge and the densities of the composites were measured using buoyancy method as per the ASTM standard D3800-16 [36]. The fibre volume fraction for these composites was measured using a modified form of burn off test given by ASTM standard D 3171 [37]. The parameters for burn off were identified for hybrids by conducting several trials by altering temperature and time for burn-off. Optical microscopy was done to check the infiltration quality and void content in the composites.

Table 3. Physical properties of the manufactured fabric reinforcements.

\begin{tabular}{ccccccc}
\hline Property & Units & Ref Carbon & Hybrid1 & Hybrid2 & Hybrid3 & Ref Glass \\
\hline Thickness at 400 g load & {$[\mathrm{mm}]$} & 0.6 & 0.7 & 0.8 & 0.8 & 0.5 \\
Thickness at 28 kg load & {$[\mathrm{mm}]$} & 0.4 & 0.6 & 0.6 & 0.5 & 0.3 \\
Areal density & {$\left[\mathrm{g} \mathrm{m}^{-2}\right]$} & 327 & 520 & 516 & 521 & 260 \\
Coverage & {$[\%]$} & 95 & 98 & 98 & 99 & 88 \\
Stitch gauge & [stitches/inch] & 10.1 & 9.8 & 9.7 & 9.6 & 9.9 \\
Stitch pitch & [stitches/inch] & 3.2 & 3.2 & 3.2 & 3.1 & 3.2 \\
\hline
\end{tabular}

\subsubsection{Tensile Properties}

Quasi-static tensile tests were conducted using a Universal Testing Machine from Instron, Norwood, MA, USA, with a maximum load capacity of $100 \mathrm{kN}$. The tensile properties (ultimate tensile strength, failure strain and modulus) of the fabricated composites were measured according to ISO 527-4 standard [38] using Type 3 specimen configuration. The test specimens were cut into strips along $0^{\circ}$ with $250 \mathrm{~mm}$ length and $25 \mathrm{~mm}$ width, as shown in Figure 4 . For the selected dimensions of coupon samples and considering the objective of conducting tensile tests in quasi-static loading conditions, the cross-head speed of $2 \mathrm{~mm} \mathrm{~min}^{-1}$ was used for the tests. The selected cross-head speed resulted in the strain rate in the range of $10^{-4} \mathrm{~s}^{-1}$ to $10^{-5} \mathrm{~s}^{-1}$ for all types of composites. For each specimen, four rectangular glass fibre reinforced composite end-tabs ( $1 \mathrm{~mm}$ thick) were bonded at the gripping portions using a cold hardening high-performance epoxy resin. A minimum of five samples was tested for each configuration. The strain in the composite was measured using a non-contact method based Advanced Video Extensometer (AVE) setup attached to the Instron UTM. The tensile strength was determined using the stress-strain curve and the tensile modulus was determined by calculating the slope of the initial linear portion of the obtained curve. 


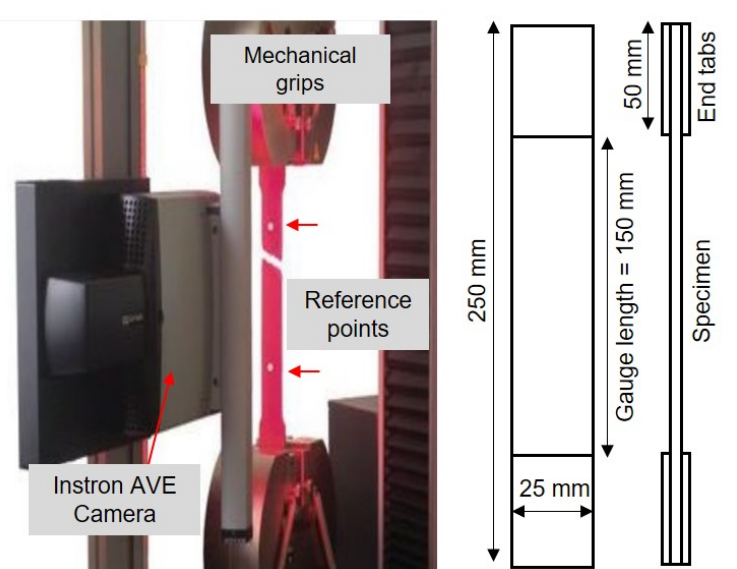

(a) Tensile test setup and specimen dimensions

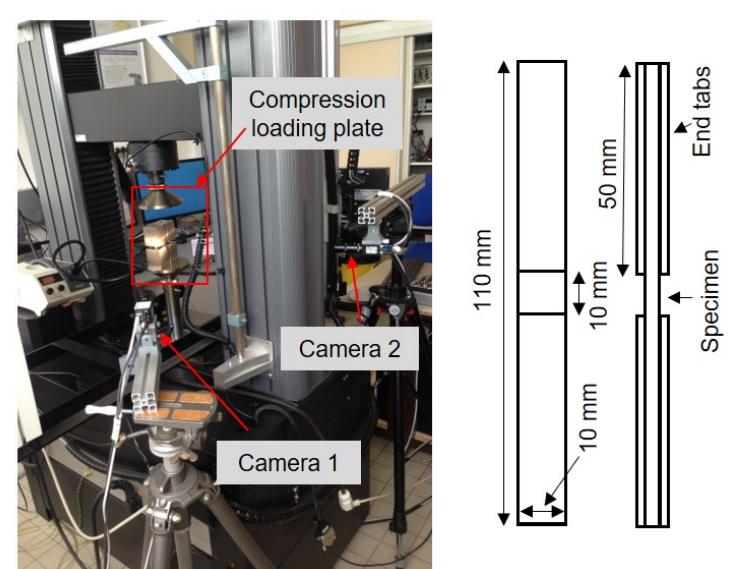

(b) Compression test setup and specimen dimensions

Figure 4. Test setup and specimen dimensions for mechanical properties characterisation: (a) tensile tests; and (b) compression tests.

\subsubsection{Compression Properties}

Quasi-static longitudinal compression tests were performed according to ISO 14126 standard [39] using an Instron Universal Testing Machine with $100 \mathrm{kN}$ load-cell. Cross-head speed was set to $1 \mathrm{~mm} \mathrm{~min}^{-1}$. The test specimens were cut into strips of $110 \mathrm{~mm}$ length and $10 \mathrm{~mm}$ width. As mentioned above, at least five samples for each composite were tested. For each specimen, four rectangular glass fibre reinforced composite end tabs were bonded at the gripping portions barring the $10 \mathrm{~mm} \times 10 \mathrm{~mm}$ central test region, as shown in Figure 4. The strain in the composite was measured using a DIC setup and image analysis. Full-field measurements were carried out using Baumer TXG20 camera (1/1.8" sensor size, $1624 \times 1236$ pixels, 8 -bits) fixed on a balanced and stabilised tripod. A region of interest was selected in central region of test zone barring the edges. Analysis of images was done according to the specifications of the VIC-3D 2013 software. Computation of 3D displacement fields was performed by discretising the region of interest into $21 \times 21$ pixel squares, with a distance of seven pixels between two successive square centres. For compression samples, two cameras were used to look at two different regions of interest in compression specimen. While the strain measurements were calculated from the DIC of the face side of the samples, the pictures from the side camera were used to understand the fracture behaviour. The measured strain from DIC was then related to the load elongation data from the UTM and the stress-strain curves were plotted using the obtained datasets. The ultimate compressive strength was determined using the stress-strain curve and the modulus in compression was determined by calculating the slope of the initial linear portion of the obtained curve.

\subsubsection{Fractography}

The fractured samples were further analysed at macroscopic and microscopic level to understand typical fracture behaviour of the composites in different tests. Scanning Electron Microscopy (SEM) using Nova NanoSEM 450 was performed to observe the fracture surface of the broken samples. The specimens were coated with $3 \mathrm{~nm}$ to $5 \mathrm{~nm}$ of gold/palladium ( $\mathrm{Au} / \mathrm{Pd}$ ) to ensure good conductivity and inhibit specimen charging. The fractured samples were cut straight near the fracture location using a diamond saw. Optical microscopy was carried out using Zeiss AX10 Lab A1 equipment with a magnification range from $5 \times$ to $100 \times$.

\section{Results and Discussion}

\subsection{Density and Fibre Volume Fraction}

Fibre Volume Fraction and density of fabricated composite panels were evaluated to ensure the quality consistency of every composite specimen prior to subsequent experiments. The density 
measurements and the fibre content from the burn-off tests are presented in Table 2 and it can be seen that the FVF for all composites is comparable. Besides this, the RTM process used proved to be a very reliable and robust process to manufacture composites. Optical microscopy images suggested presence of no major voids and the void content on average was lower than $0.75 \%$ in the samples. It is also apparent that, by introduction of glass fibres into the fabrics and composite layup, the density of subsequent composite increased. A stitched image showing the overview of cross-section for $\mathrm{H} 1$ intraply hybrid composite can be seen in Figure 5a and a zoomed-in magnified image is presented in Figure $5 b$. The composite volume fraction $\left(V_{c}\right)$ or hybrid ratio defined as the ratio of volume of one of the constituents (here, carbon) of the hybrid composite to the volume of hybrid composite was 0.62 for the hybrid composites.

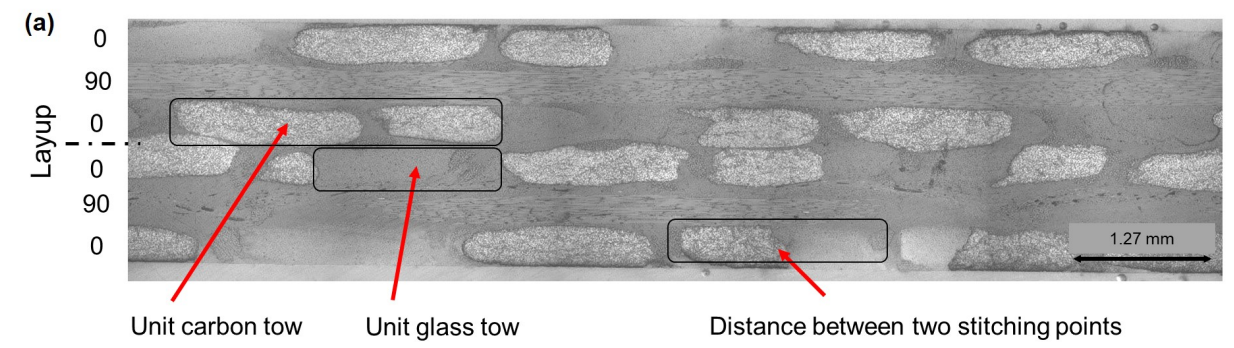

(b)

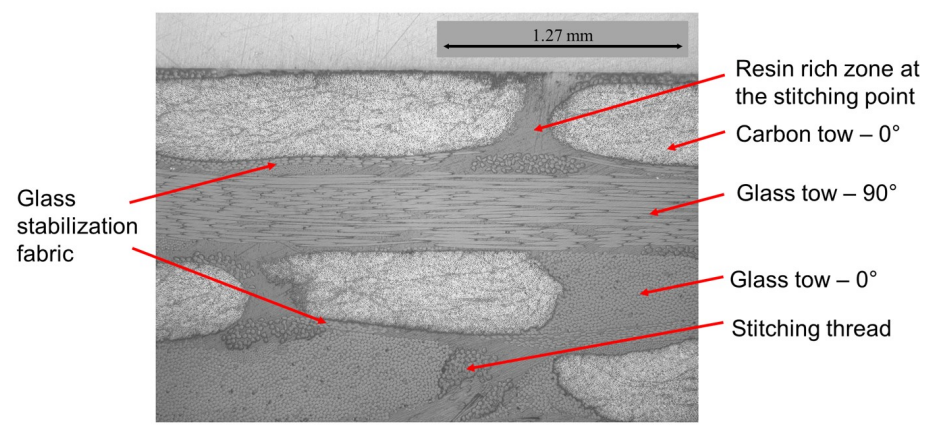

Figure 5. Optical microscopy images of $\mathrm{H} 1$ intraply hybrid composite: (a) overview of the cross-section; and (b) zoomed-in.

\subsection{Tensile Properties}

\subsubsection{Stiffness}

For the developed composites, the hierarchy of tensile modulus is as follows: "R1 (Reference carbon composite)" > "H3 $\approx \mathrm{H} 2 \approx \mathrm{H} 1$ (Intraply hybrid composites)" > "I1 (Interply hybrid composite)" $>$ "R2 (Reference glass composite)". The last column in Table 4 provides the mean values $( \pm$ standard deviation associated with a 90\% confidence level) for Young's modulus for each composite type.

Table 4. Tensile properties of composites along $0^{\circ}$; mean values of properties and standard deviation associated with $90 \%$ confidence level are presented.

\begin{tabular}{lccc}
\hline Composites & $\begin{array}{c}\text { Ultimate Tensile Strength } \\
\sigma_{\mathrm{t}}[\mathrm{MPa}]\end{array}$ & $\begin{array}{c}\text { Tensile Failure Strain } \\
\boldsymbol{\varepsilon}_{\mathrm{t}}[\%]\end{array}$ & $\begin{array}{c}\text { Tensile Modulus } \\
\mathbf{E}_{\mathbf{t}}[\mathrm{GPa}]\end{array}$ \\
\hline R1-Ref carbon & $1165( \pm 43)$ & $1.70( \pm 0.04)$ & $69.8( \pm 2.1)$ \\
H1-Intraply (1C1G) & $935( \pm 58)$ & $1.60( \pm 0.10)$ & $60.8( \pm 3.0)$ \\
H2-Intraply (2C2G) & $964( \pm 43)$ & $1.67( \pm 0.10)$ & $59.3( \pm 1.2)$ \\
H3-Intraply (3C3G) & $1024( \pm 49)$ & $1.67( \pm 0.09)$ & $60.5( \pm 2.0)$ \\
I1-Interply & $898( \pm 44)$ & $1.82( \pm 0.10)$ & $50.2( \pm 0.8)$ \\
R2-Ref glass & $587( \pm 20)$ & $2.74( \pm 0.13)$ & $21.8( \pm 0.5)$ \\
\hline
\end{tabular}

* Values in brackets signify the statistical uncertainty and are the standard deviations associated with $90 \%$ confidence level, calculated using "Guide to the expression of uncertainty in measurement" (GUM) [40]. 
The stiffness for three intraply hybrid composites, $\mathrm{H} 1, \mathrm{H} 2$ and $\mathrm{H} 3$, are not significantly different and their mean stiffness values are $60.8 \mathrm{GPa}, 50.3 \mathrm{GPa}$ and $60.5 \mathrm{GPa}$, respectively. These values suggest there is no effect of tow dispersion on the stiffness of intraply hybrid composites (Figure 6a). Several researchers $[1,3,5]$ showed that the tensile modulus for hybrid composites obey a linear Rule of Mixtures, but most of the reported studies were on unidirectional composites. For cross ply layup, such as in the current study, the transverse direction reinforcements where Rule of Mixtures are not linear and often less accurate can influence the Young's modulus in longitudinal directions. The intraply hybrids show a positive deviation in the Young's modulus when compared to that obtained from linear RoM, while I1 (50.2 GPa) demonstrates stiffness nearest to the theoretically obtained value (51.5 GPa) using the linear RoM. Positive deviation from Rule of Mixtures for hybrid composites were also reported by Ren et al. [21] and Taketa [41]. It was found that the tensile modulus and strength of the intraply hybrid composites are slightly higher than those of the interply hybrid composites. This may be attributed to better dispersion of high modulus carbon and low modulus glass fibres in the intraply hybrids compared to those in interply, leading to better load transferring from fibres to fibres in the intraply composites than in the interply composite.

\subsubsection{Failure Characteristics}

The hierarchy of tensile strength is as follows: "R1 (Reference carbon composite)" > "H3 $\approx$ H2 and H1 (Intraply hybrid composite)" > "I1 (Interply hybrid composite)" > "R2 (Reference glass composite)".

The hierarchy of tensile failure strain is as follows: "R2 (Reference glass composite)" > "I1 (Interply hybrid composite)" > "H3, H2 and H1 (Intraply hybrid composite)" $\approx$ "R1 (Reference carbon composite)".

(a)

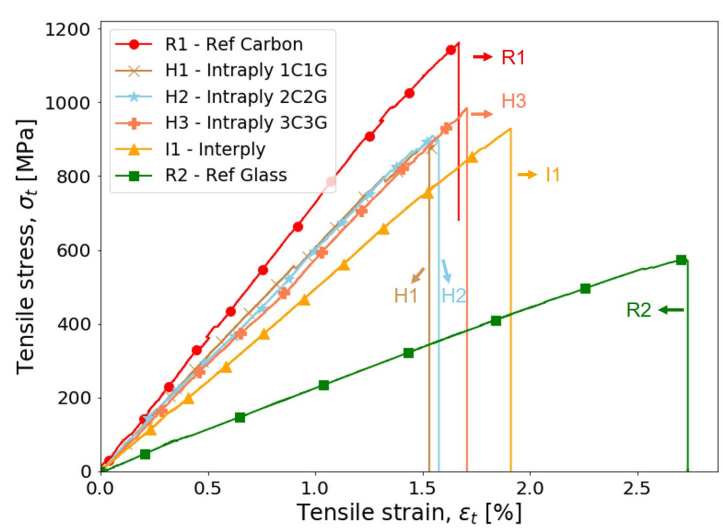

(b)

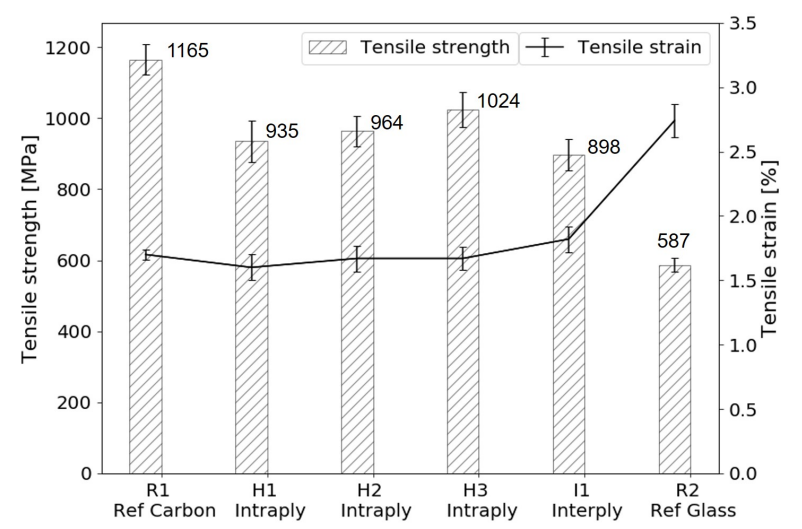

Figure 6. Tensile properties of composites along $0^{\circ}$ : (a) stress-strain plot; and (b) failure characteristics. In (a), representative curves with failure characteristics closer to the average values reported in Table 4 for each composite type are presented.

The hierarchy of tensile strength for all composites follow a trend similar to that of tensile stiffness, the difference being that $\mathrm{H} 1, \mathrm{H} 2$ and $\mathrm{H} 3$ do not show similar strengths, but they showed identical modulus. The failure strain as expected is highest for glass fibre composite R2. For I1, contrary to the stiffness and strength properties, its tensile failure strain lies higher in the hierarchy than the three intraply hybrids $\mathrm{H} 1, \mathrm{H} 2$ and $\mathrm{H} 3$.

The failure strain of interply hybrid composite I1 is more than that of intraply hybrids H1, $\mathrm{H} 2$ and H3. In other words, for the same hybrid ratio, the hybrids made by combining carbon and glass on a ply-per-ply basis give higher tensile failure strain than the tow-per-tow hybridised composites. For interply hybrid composite I1, the carbon layers are sandwiched between glass layers; hence, possible damage evolution in carbon layers during tensile loading is constrained because of 
surrounding glass layers, resulting in carbon layers withstanding more strain before failure of the layer. This phenomenon was as also reported by Pandya et al. [25] and Swolfs et al. [2]. Even though the intraply hybrids $\mathrm{H} 1, \mathrm{H} 2$ and $\mathrm{H} 3$ have a significant proportion of high elongation glass fibre in their structure, they tend to not affect the failure development in the carbon fibres in the exterior layers as they are not sufficiently constrained and hence show no improvement in the failure strain when compared to the reference carbon composites. Kretsis [1] in his review paper analysed literature data prior to 1987 and clearly demonstrated that the hybrid effect increased with decreasing high modulus fibre content. Swolfs et al. [2] further suggested caution in interpreting the failure strain enhancements reported earlier, as the studies reported $-66 \%$ to $+166 \%$ failure strain enhancements, which is unrealistic. Multiple reasons can be identified for these unrealistic values, e.g. improper testing of reference carbon composites or low quality carbon fibres during earlier times.

The tensile strength for interply and intraply hybrids falls in between the values for the two reference composites $\mathrm{R} 1$ and $\mathrm{R} 2$ (1165 MPa and $587 \mathrm{MPa}$, respectively). The tensile strength for Interply hybrid I1 is $898 \mathrm{MPa}$ and it is the lowest among the hybrids. An improvement in the tensile strength of intraply hybrids was observed as the carbon and glass tows are blocked together in the intraply hybrids from $935 \mathrm{MPa}$ for $\mathrm{H} 1$ to $964 \mathrm{MPa}$ and $1024 \mathrm{MPa}$ for $\mathrm{H} 2$ and $\mathrm{H} 3$, respectively (Figure 6b). This improvement in the strength for the intraply variants can be attributed to the effect of hybridisation and the changes in their failure behaviour. Among the hybrids, the intraply hybrids $\mathrm{H} 1, \mathrm{H} 2$ and $\mathrm{H} 3$ have tensile strength $4.1 \%, 7.4 \%$, and $14.0 \%$ higher, respectively, than the interply hybrid I1. Ikbal et al. [28] reported higher strength for interply hybrids for unidirectional composites, although in their studies the difference between interply and intraply was about $5 \%$ for strength and $2 \%$ for modulus, which is not very significant and can be influenced by several processing and testing parameters. In the current study, higher dispersion of carbon and glass fibres in the intraply configuration led to better load transferring from fibre to fibre and hence intraply hybrids ( $\mathrm{H} 1, \mathrm{H} 2$ and H3) demonstrate higher strengths than the interply composite I1.

\subsection{Compression Properties}

\subsubsection{Stiffness}

For the developed composites, the hierarchy of compressive modulus is as follows: "R1 (Reference carbon composite) $\approx \mathrm{H} 2$ and $\mathrm{H} 3$ (Intraply hybrid composite)" > "H1 (Intraply hybrid composite) $\approx \mathrm{I} 1$ (Interply hybrid composites)" > "R2 (Reference glass composite)".

The last column in Table 5 provides the mean values ( \pm standard deviation associated with $90 \%$ confidence level) for compressive modulus for each composite type. It can be seen that the hybrid composites $\mathrm{H} 2$ and $\mathrm{H} 3$ have a comparable compressive stiffness to the reference carbon composite $\mathrm{R} 1$ (see Table 5 and Figure 7a). When compared to the theoretical stiffness ( $42.1 \mathrm{GPa}$ ) calculated using rule of mixture (using the stiffness's of R1, R2 and hybrid ratio of 0.62), configurations H1 (45.9 GPa) and I1 (45.3 GPa) do not show significant difference in longitudinal compression. Hence, interply hybrid I1 is shown to obey a linear Rule of Mixture for both tensile and compressive modulus while the intraply hybrid $\mathrm{H} 3$ shows a positive deviation in both cases. Among hybrids, the intraply $\mathrm{H} 1$ has the highest ratio (1.32) of tensile to compression modulus, which is the same as for R1, while it is lowest (1.11) for I1 interply hybrid due to changed failure behaviour in I1 owing to twice the number of ply interfaces in its structure.

\subsubsection{Failure Characteristics}

The hierarchy of compressive strength is as follows: "H3, H2 (Intraply hybrid composite)" > "R1 (Reference carbon composite)" > "H1 (Intraply hybrid composite)" > "I1 (Interply hybrid composite)" $>$ "R2 (Reference glass composite)". 
The hierarchy of compressive failure strain is as follows: "R2 (Reference glass composite)" > "H3 (Intraply hybrid composite)" > "R1 (Reference carbon composite) $\approx$ H2 and H1 (Intraply hybrid composite)" > "I1 (Interply hybrid composite)".

Table 5. Compressive properties of composites along $0^{\circ}$; mean values of properties and standard deviation associated with $90 \%$ confidence level are presented.

\begin{tabular}{lccc}
\hline Composites & $\begin{array}{c}\text { Ultimate Compressive Strength } \\
\sigma_{\mathrm{c}}[\mathrm{MPa}]\end{array}$ & $\begin{array}{c}\text { Compressive Strain } \\
\boldsymbol{\varepsilon}_{\mathrm{c}}[\%]\end{array}$ & $\begin{array}{c}\text { Compressive Modulus } \\
\mathrm{E}_{\mathrm{c}}[\mathrm{GPa}]\end{array}$ \\
\hline R1-Ref carbon & $492( \pm 22)$ & $0.98( \pm 0.09)$ & $52.5( \pm 2.0)$ \\
H1-Intraply (1C1G) & $484( \pm 40)$ & $1.00( \pm 0.19)$ & $45.9( \pm 3.1)$ \\
H2-Intraply (2C2G) & $515( \pm 13)$ & $0.97( \pm 0.09)$ & $52,7( \pm 2.6)$ \\
H3-Intraply (3C3G) & $535( \pm 36)$ & $1.12( \pm 0.06)$ & $51.3( \pm 8.2)$ \\
I1-Interply & $388( \pm 16)$ & $0.91( \pm 0.08)$ & $45.3( \pm 2.5)$ \\
R2-Ref glass & $316( \pm 30)$ & $1.29( \pm 0.18)$ & $25.0( \pm 3.5)$ \\
\hline
\end{tabular}

(a)

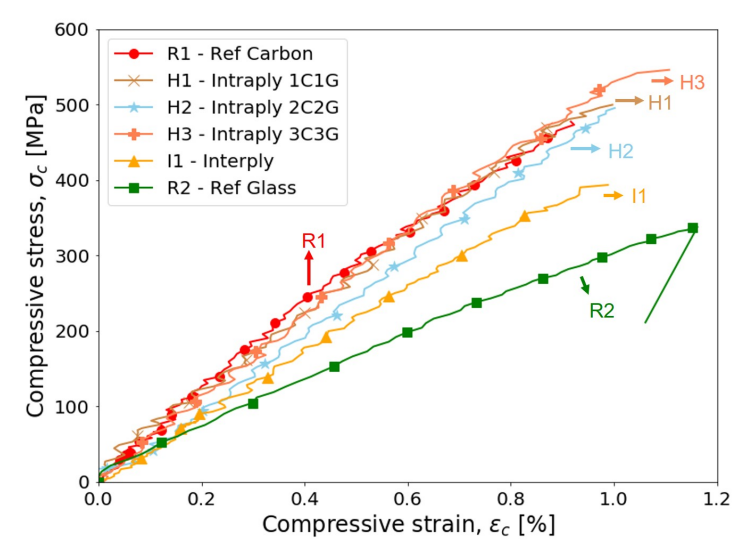

(b)

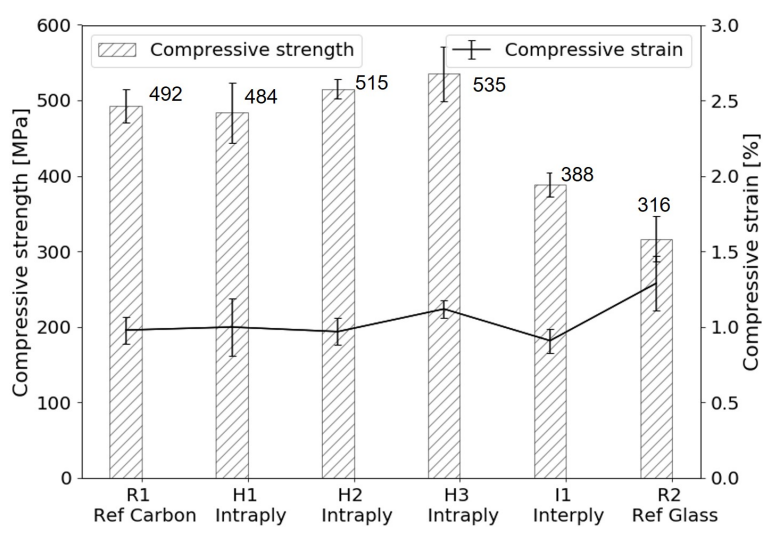

Figure 7. Compressive properties of composites along $0^{\circ}$ : (a) stress-strain plot; and (b) failure characteristics. In (a), representative curves with failure characteristics closer to the average values reported in Table 5 for each composite type are presented.

I1 had the highest failure strain in tension; on the contrary, in compression, the I1 hybrid made by combining carbon and glass on a ply per ply basis gives lower failure strain than placing carbon and glass tows in the individual fabric. This behaviour of I1 in compression (and hence its lower compressive strength behaviour) can be attributed to multiple factors: (i) the I1 composites have more ply interfaces, as it has twice the number of layers; and (ii) I1 has low modulus glass fibres in the exterior of the layup, which makes it more susceptible to the local buckling (initiated during or after delamination) occurring during longitudinal compression test. Delamination in I1 composites was prominently observed and in compressive loading I1 did not assist a gradual failure behaviour as in tensile loading. Although the specimen width in compression (for $\mathrm{H} 2$ and $\mathrm{H} 3$ ) was lower than the repeating unit cell width in the fabrics, the standard deviation for strength and failure strain does not show a significant difference from other composites. The failure strain for intraply hybrids are equal to or higher than the reference carbon composite and this is attributed to better load transfer between the fibres due to dispersion of carbon and glass fibres in the cross-section.

The compressive strength values for the interply I1 (388 MPa) falls in between the values for the two reference composites, but the compressive strengths for intraply hybrids $\mathrm{H} 1, \mathrm{H} 2$ and $\mathrm{H} 3$ are very similar or slightly higher than that for reference carbon composite R1. Such a trend for interply hybrid bi-directional composites was reported by Pandya et al. [25]; while Ikbal et al. [42] and Ikbal et al. [28] reported a trend of about $60 \%$ reduction of compressive strengths for hybrids when compared to reference carbon composites for unidirectional composites. It is important to mention that precise measurement of reference composites is consequential to interpret the change for hybrids, and this is 
more difficult for unidirectional composites than for the current work on multidirectional composites. For intraply hybrids, although the face of the specimen contained carbon and glass rovings side by side, the strain during compression observed through DIC was uniform over the width. Furthermore, the final failure on face and sides show failure of both carbon and glass tows in compression and then through other mechanisms such as delamination and buckling, as shown in Figure 8 for H1 composite specimen.
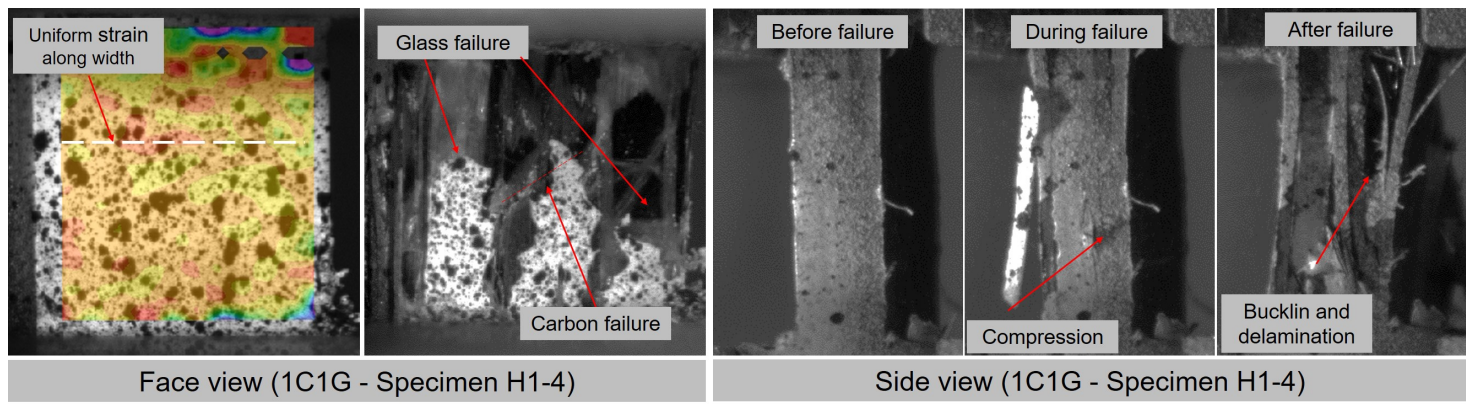

Figure 8. Pictures from camera setup during compression tests: DIC measurements on face side and fracture observation on the thickness of specimens.

When compared to the reference composite R1, the strengths of hybrid composites $\mathrm{H} 2$ and H3 show an increase of $4.6 \%$ and $8.6 \%$, respectively, while I1 shows a reduction of $21.2 \%$. As also observed during tensile loading, a gradual improvement in compressive strength (484 MPa, $515 \mathrm{MPa}$, and $535 \mathrm{MPa}$ for $\mathrm{H} 1, \mathrm{H} 2$ and $\mathrm{H} 3$, respectively) for intraply hybrids was observed as the carbon and glass tows are blocked together in the intraply hybridisation, as can also be seen in Figure $7 \mathrm{~b}$.

\subsection{Damage Morphology}

During tensile loading, it was observed that the reference composites R1 and R2 failed suddenly in a catastrophic failure, although the cracking noise could be heard during the entire duration of test for both composites. All carbon samples broke yielding two separate pieces or sometimes three pieces because of secondary failure induced by the shock of rapid elastic recovery. Glass composite R2 still had some unbroken rovings, which connected the two pieces across the tensile failure line. Hybrid composites also failed catastrophically and this catastrophic failure in them can be attributed to a higher proportion of carbon fibres in their structure. Macroscopic observations show that the three intraply hybrid samples show very similar kinds of failure surface. The failure tends to show that, as the strain increases, the carbon fibre fail first (see Figure 9a), causing stress concentrations and matrix cracking in adjoining regions, and, as the strain increases, a whole carbon fibre bundle (tow) fails. The catastrophic tow failure causes longitudinal splitting of carbon tow from the specimen and large-scale pullout in adjoining regions, further leading to composite failure. The glass fibre tow in the hybrid ply at the surface here can be clearly seen broken and delaminated from the surface in Figure $9 \mathrm{~b}$. The area of damage (and delamination for glass tows) witnessed for these intraply hybrid composites is higher than that for reference and interply composites (see Figure 9c). For interply I1, carbon ply fails catastrophically on reaching the maximum stress and further this failure of carbon ply leads to the catastrophic failure in the glass plies. Interlayer delamination can also be prominently seen in all hybrids, although for these composites secondary failure was not observed.

For both tensile and compression tests, several researchers [2,13,31] reported difficulties in measuring the baseline tensile failure strain of a high strength unidirectional composite, against which the strain at failure of the hybrid is compared to determine the hybrid effect. It is reported for unidirectional composites the stress concentration during testing can lead to underestimation of reference failure strain and hence overestimation of hybrid effect. In the current work, as the composites consisted of a cross-ply layup and that a proper care for end-tabbing of the specimen (see Section 2.3.2) was carried out, this overestimation of the hybrid effect is reasonably avoided. 
The failure for most samples, hybrids and non-hybrids occurred in the central regions of the gauge length hints at a very limited stress concentration effect for the tested composites.
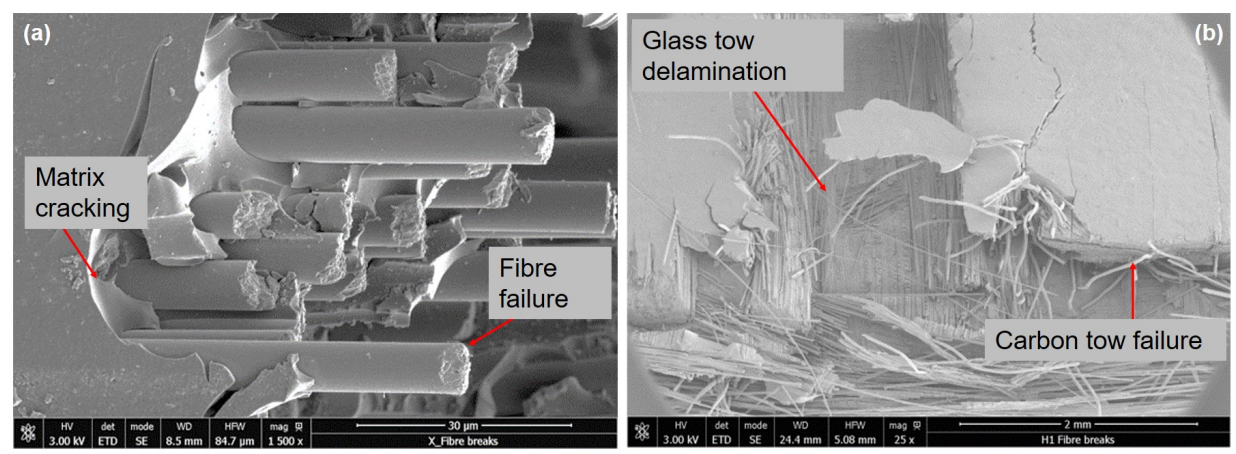

(c)

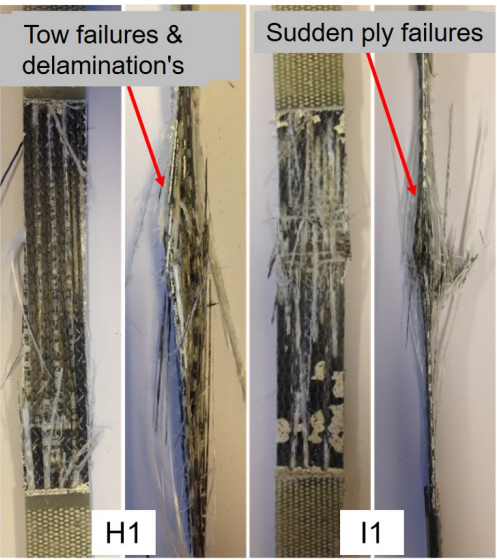

Figure 9. Fractography of failure of composites in tensile loading: (a) fibre breakage and matrix cracking; (b) glass tow delamination; and (c) H1 and I1 failed specimens.

All the samples loaded in longitudinal compression show catastrophic failure, but no samples were observed to be completely separated into two halves. It was observed that the load applied at two ends concentrate at the center of the test zone. As the load increased, for interply hybrids, the failure catastrophically occurred by forming a major crack at the central plane and enlargement of this crack into a through-the-thickness crack, as shown in Figure 10b. For intraply hybrids, the failure was similar for all three types. Delamination between the layers was more prominent and larger failure surface was noted specifically for intraply hybrids (see Figure 10a,c) because the two fibres in the same layer had a very different failure strain.
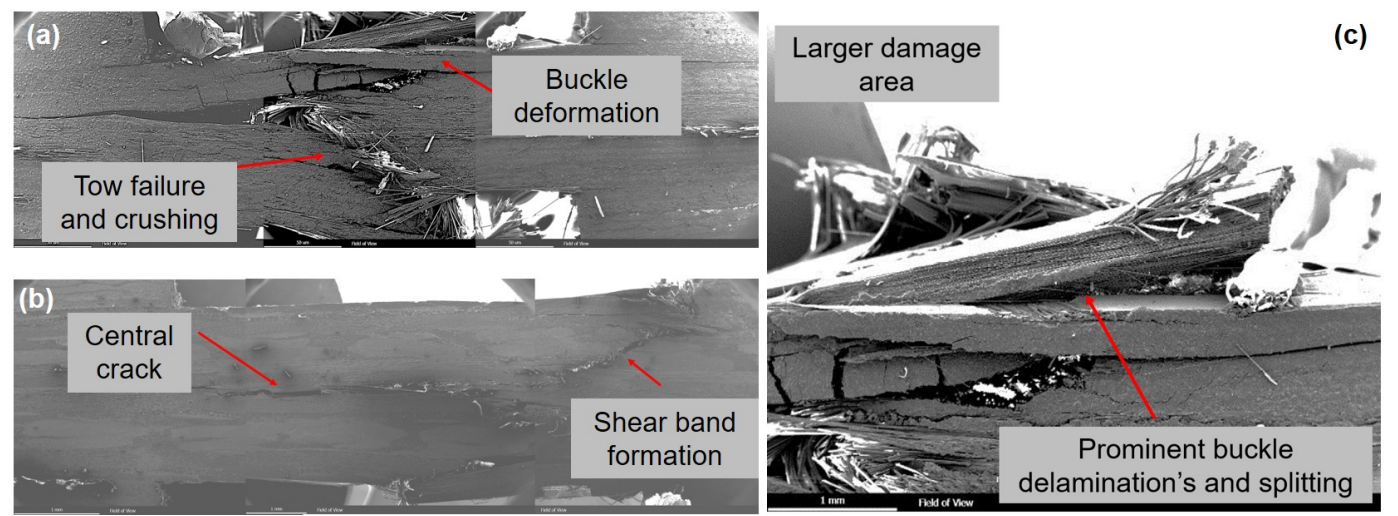

Figure 10. Fractography of failure of composites in compressive loading: (a) typical failure in H3; (b) typical failure in I1; and (c) magnified, typical failure in $\mathrm{H} 3$. 


\subsection{Hybrid Effect}

\subsubsection{Improvement in Failure Strain}

The failure strain in tension and compression normalised to the failure strain of low elongation reference carbon composites in respective loading conditions is presented in Figure 11a,b. It can be derived from the results in Table 4 and Figure 11a that in tensile loading there is a slight negative hybrid effect or no hybrid effect for intraply hybrid composites while the interply hybrid composite I1 shows a positive hybrid effect of $+7.4 \%$. This positive hybrid effect comes from reduced damage evolution in carbon layers because of constraints provided by surrounding glass layers, resulting in carbon layers withstanding more strain before failure of the layer. Similarly, for compressive loading conditions, the intraply hybrids $\mathrm{H} 1$ and $\mathrm{H} 2$ showed no hybrid effect, while the intraply hybrid $\mathrm{H} 3$ showed a positive hybrid effect of about $+14 \%$. Opposite to its behaviour in tension, the ply-per-ply hybrid I1 in compression shows a negative hybrid effect of $6.4 \%$, as shown in Figure $11 \mathrm{~b}$, and this can be attributed to the number of layers, complex failure mode and prominent delamination during the compressive loading.

(a)

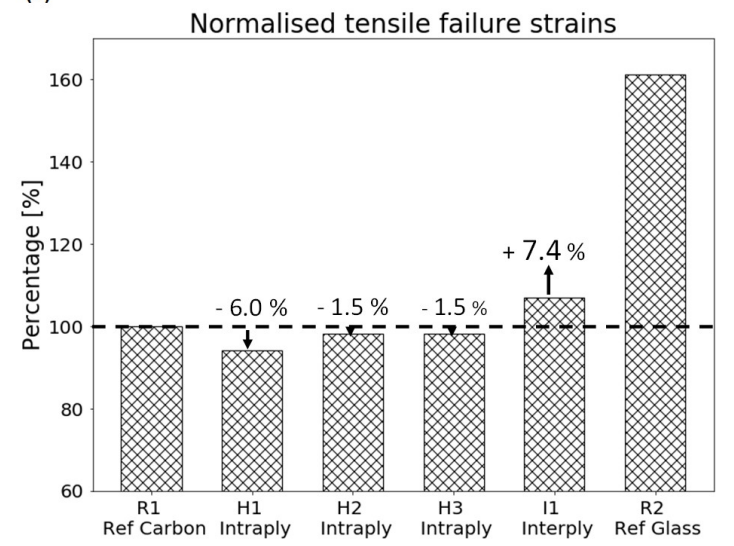

(b)

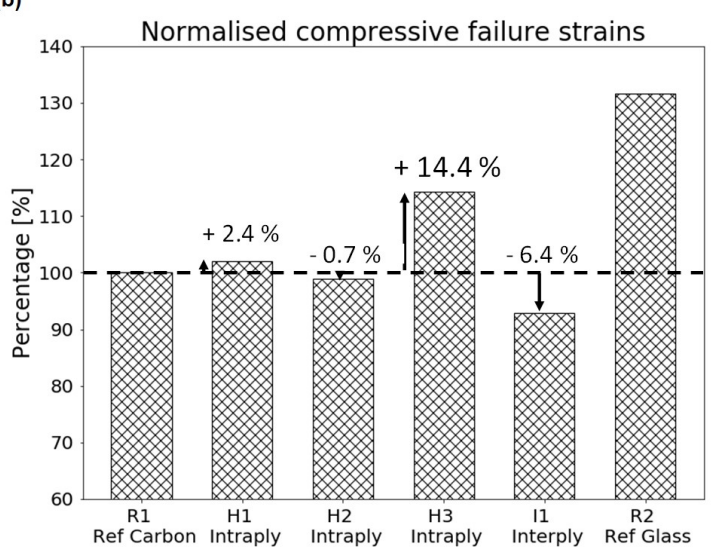

Figure 11. Normalised failure strain for tested composites: (a) in tensile loading; and (b) in compression loading.

\subsubsection{Deviation from Rule of Mixtures (RoM)}

Tensile and compressive strength of hybrid composite as a function of the volume fraction of carbon composite $\left(V_{\mathrm{c}}\right)$ is presented in Figure 12a,c, respectively. These figures are plotted based on mechanics of materials approach [43] to strength under quasi-static loading along the $0^{\circ}$ direction. Here, lines $\mathrm{AB}$ and $\mathrm{BC}$ represent the strength of the hybrid composite as per bi-linear RoM for different carbon composite volume fractions $\left(V_{\mathrm{c}}\right)$. It has to be noted that line $\mathrm{AB}$ represents the RoM when the strength property is dominated by glass fibres, typically for lower carbon composite volume fractions and line $\mathrm{BC}$ represents the RoM for composite with larger carbon composite volume fraction. When the volume fraction of carbon composite is zero, it represents reference glass fibre composite R2, whereas, when the volume fraction of carbon composite equals one, it represents reference carbon fibre composite R1. In Figure 12a,c, the volume fraction of carbon composite at B is $V_{c}=0.15$. Experimentally obtained mean strength values for hybrid composites H1, H2, H3 and I1 are denoted by H1, H2, H3 and I1, respectively; mean values are plotted on the left hand side plots while individual values for strength of every hybrid specimens tested are plotted on the right hand side plots in Figure 12. 
(a)

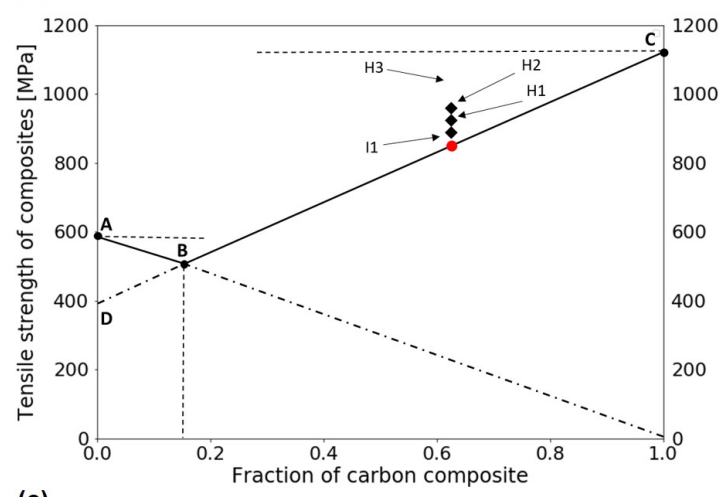

(c)

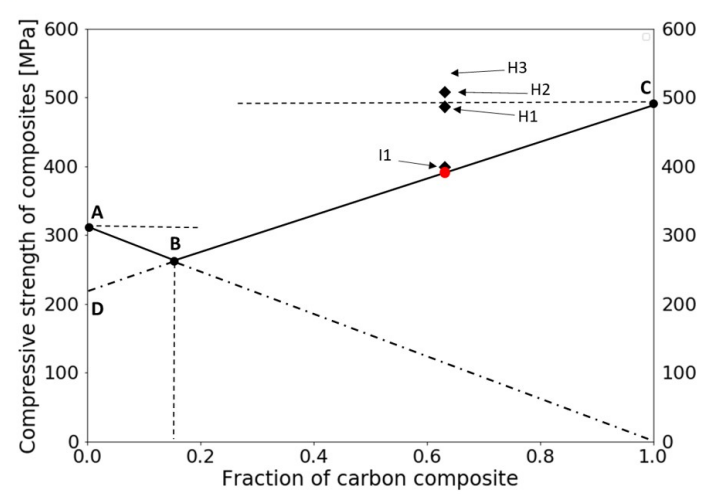

(b)

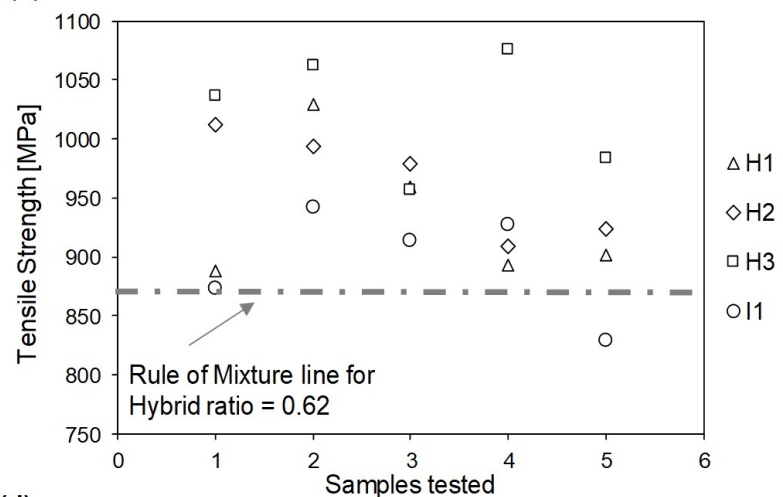

(d)

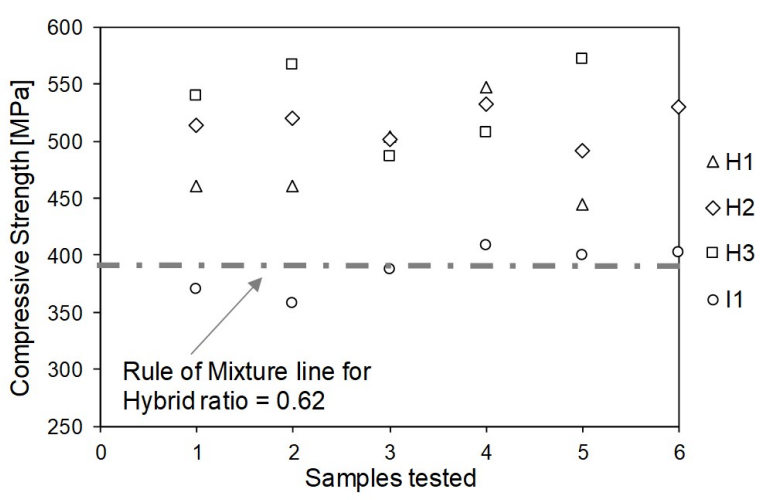

Figure 12. Synergistic effect and strength of composites under quasi-static loading: (a) mean strength in tension; (b) strength of all hybrid specimens in tension; (c) mean strength in compression; and (d) strength of all hybrid specimens in compression

The tensile strength obtained using RoM for a hybrid composite volume fraction of 0.62 is $869 \mathrm{MPa}$, whereas those for intraply hybrid composites $\mathrm{H} 1, \mathrm{H} 2$ and $\mathrm{H} 3$ are $935 \mathrm{MPa}, 964 \mathrm{MPa}$ and $1024 \mathrm{MPa}$, respectively. This higher experimental strength is because of synergistic effect obtained by hybridisation. For interply hybrid I1, the experimental value of $898 \mathrm{MPa}$ is slightly higher than the value obtained from the RoM. Details of calculation of strength of hybrid composites as per RoM and calculation of hybrid effect is presented in Appendices A and B, respectively.

Similarly, compressive strength for hybrid composite can be calculated from RoM (as discussed in Appendix A), and this theoretical strength value for the hybrids (with $V_{c}=0.62$ ) was found to be $391 \mathrm{MPa}$. It can be seen in Figure 12c,d that intraply hybrids H1, H2 and H3, with mean strengths of $484 \mathrm{MPa}, 515 \mathrm{MPa}$ and $535 \mathrm{MPa}$, respectively, show a positive synergistic for compressive strength. Interply hybrid I1 shows no synergistic effect and its strength obtained experimentally coincides with the value obtained from RoM.

Further, the statistical uncertainties for the mean tensile strength values calculated using GUM [40] for $\mathrm{H} 1, \mathrm{H} 2$ and $\mathrm{H} 3$ at $90 \%$ confidence level are $58 \mathrm{MPa}, 43 \mathrm{MPa}$ and $49 \mathrm{MPa}$, respectively. This means, for example, for $\mathrm{H} 3$, out of 100 sampling tests, $90 \%$ of the time, the mean strength of the samples will lie in the range of $975 \mathrm{MPa}$ to $1073 \mathrm{MPa}$ (i.e., $1024 \pm 49 \mathrm{MPa}$ ). The mean value for $\mathrm{H} 3$ in this range is still higher than the theoretical/Rule of Mixture value for strength of hybrid and hence confirms a positive hybrid effect in tensile strength for $\mathrm{H} 3$ composite and this hybrid effect is about $+17.8 \%$. Similar uncertainty analysis confirmed the positive hybrid effect in tension for $\mathrm{H} 1$ and $\mathrm{H} 2$, with values of $+7.6 \%$ and $+10.9 \%$, respectively. For I1, the uncertainty at $90 \%$ confidence level is $44 \mathrm{MPa}$, which makes the range in which $90 \%$ of the time the sample mean will lie $854 \mathrm{MPa}$ to $942 \mathrm{MPa}$. This suggests that, although the mean strength for I1 is 3.3\% higher than Rule of Mixtures (869 MPa), the mean sample strength does not confirm a significant positive hybrid effect in I1 interply composite. 
Similar analysis of the mean compressive strengths and uncertainties confirmed a positive hybrid effect for compressive strengths for intraply hybrid composites. This synergistic effect because of hybridisation was observed to be $+23.8 \%$, $+31.8 \%$ and $+36.9 \%$ for $\mathrm{H} 1, \mathrm{H} 2$ and $\mathrm{H} 3$ intraply hybrids, respectively. It can also be concluded that the synergistic hybrid effect by combining glass and carbon fibres for a composite is higher in compression loading than that in tensile loading.

\section{Conclusions}

This study investigated the potential and mechanical performance of intraply and interply hybrid composites for newer light-weighting and structural applications. Using the analysis of the results and observations made during the fabrication and testing of the composite laminates, the following conclusions can be drawn.

- $\quad$ Altered dispersion of tows due to blocking of carbon and glass tows in H1, H2 and H3 hybrid composite did not affect the tensile and compressive stiffness of composites. The interply hybrid I1 demonstrates lower stiffness, about $16.7 \%$ and $9.4 \%$ lower than the average for intraply hybrids in tensile and compressive loading conditions, respectively.

- $\quad$ Failure of composites in tension and compression was catastrophic for both hybrids and non-hybrid composites. For hybrid composite, the catastrophic failure can be attributed to the higher carbon fibre volume fraction $\left(V_{c}\right)$ in these composites.

- Macroscopic and microscopic observations confirmed the failure mode in tension is dominated by carbon fibre failure. For intraply hybrids, delamination of the glass tows from the surface after the carbon failure was distinctly observed, while for interply hybrid a brush-like effect similar to carbon composite R1 was observed. The compression failure for interply hybrid I1 owing to its layup structure was observed to be most complex with several failure phenomenon occurring simultaneously leading to the final failure.

- $\quad$ For I1 in tensile loading, a positive hybrid effect of about $+7.4 \%$ in failure strain was observed and this can be attributed to the reduced damage evolution in carbon layers because of constrains provided by glass layers. In compression, however, increased number of layers and complex failure mechanisms in compression led to a negative hybrid effect of $-6.4 \%$ for I1 compressive failure strain.

- $\quad$ For hybrid composites, a synergistic effect is observed for strength in tension and compression when compared to the strength obtained by the rule of mixtures. The results demonstrate a positive synergy/hybrid effect for all intraply hybrids.

- For intraply hybrids, the effect of tow dispersion was demonstrated. It was observed that composite H3 (with three carbon and three glass tows blocked along width) has superior performance in tension and compression compared to $\mathrm{H} 1$ and $\mathrm{H} 2$. Hybrids $\mathrm{H} 1, \mathrm{H} 2$ and $\mathrm{H} 3$ show a synergistic effect (deviation from RoM) of $+7.5 \%,+10.9 \%$ and $+17.8 \%$ in tensile strength and $+23.8 \%,+31.8 \%$ and $+36.9 \%$ in compressive strength, respectively.

- The ratio of tensile to compressive strength is similar (about 1.9) for all intraply hybrids, and it is highest (2.3) for ply level hybrid I1, which can be attributed to the diminished compression performance of I1 hybrid. For similar $V_{c}$, the tow level hybrids shows overall better performance in mechanical loading conditions when compared to the composites hybridised at ply level.

Partial replacement of carbon fibres by glass fibres in high volume applications such as wind blades or semi-structural automotive component offers prospects for use of composite materials as a viable economic option. Along with cost savings in general, intraply hybrids such as those with 3C3G tow dispersion offer tremendous hybridisation potential for applications such as skis or other sports/leisure products. Tow level hybrids show synergistic effect in both tensile and compressive strengths while not adversely affecting the failure strain properties. Ply level hybrids can offer cost savings but may not prove to be a suitable choice for composites subjected to complex loading conditions. Interply hybrids, however, slightly improve failure strain in tension, 
but demonstrate negative synergy in all other properties; hence, this configuration should not be chosen for structural applications.

Author Contributions: Data curation, A.R.; Formal analysis, A.R.; Funding acquisition, S.J., P.S. and V.S.; Investigation, A.R.; Methodology, A.R., V.S. and S.J.; Project administration P.S.; Supervision and validation, V.S., S.J. and L.L.; Writing—original draft, A.R.; and Writing—review and editing, A.R., V.S., P.S., S.J. and L.L. All authors have read and agreed to the published version of the manuscript.

Funding: The research leading to these results was done within the framework of the FiBreMoD project and received funding from the European Union's Horizon 2020 research and innovation programme under the Marie Sklodowska-Curie grant agreement No. 722626.

Acknowledgments: The authors acknowledge and thank Julie Fourel, Claude Soubeyrand and Jean-Christophe Teissedre for fruitful discussions in the process of composite fabrication and characterization.

Conflicts of Interest: The authors declare no conflict of interest.

\section{Appendix A. Calculation of Tensile Strength of Hybrid Composite}

Tensile strength of unidirectional composites is calculated starting with fibre and matrix properties and volume fractions. A similar approach is used for the calculation of strength of hybrid composites starting with properties of carbon fibre composite and glass fibre composite and composite volume fraction. It has to be noted that, at lower carbon composite volume fractions, the property of hybrid composites would be governed by glass fibre composites, whereas, at higher carbon composite volume fractions, it would be governed by carbon fibre composites.

Hence, at lower carbon composite volume fractions (in tension):

$$
\sigma_{\max }^{h}=\sigma_{\max }^{g} \times\left(1-V_{c}\right)
$$

and, at higher carbon composite volume fractions (in tension):

$$
\sigma_{\max }^{h}=\sigma_{\max }^{c} \times V_{c}+\left(\sigma^{g}\right)_{\varepsilon_{\max }^{c}} \times\left(1-V_{c}\right)
$$

where $\sigma_{\max }^{h}$ is the tensile strength of hybrid composite; $\sigma_{\max }^{c}$ is the tensile strength of carbon composite; $\sigma_{\max }^{g}$ is the tensile strength of glass composite; $\left(\sigma^{g}\right)_{\varepsilon_{\max }^{c}}$ is the stress in glass composite corresponding to ultimate strain of carbon composite; and $V_{c}$ is the carbon composite volume fraction.

Sample calculations for hybrid composite under in-plane tensile loading can be done using: $V_{c}=0.62 ; \sigma_{\max }^{c}=1165 \mathrm{MPa}, \varepsilon_{\max }^{c}=1.7 \%$, and $\sigma^{g}=386 \mathrm{MPa}$ Now, using Equation (A2),

$$
\sigma_{\max }^{h}=869 \mathrm{MPa}
$$

Similar calculations can be done for in-plane compressive strength of hybrid composites.

\section{Appendix B. Calculation of Hybrid Effect}

For change in failure strain (tensile and compression) in hybrids, the hybrid effect $(\lambda)$ is calculated from Equation (A3) below. Here, an increase in the failure strain of hybrid composites over failure strain of reference low elongation composite is considered to be positive hybrid effect.

$$
\lambda_{\text {failure strain }}=\frac{\varepsilon_{H}}{\varepsilon_{L E}}-1
$$

where $\varepsilon_{H}$ is the failure strain for hybrid composite and $\varepsilon_{L E}$ is the failure strain for low elongation composite. For the tensile and compressive strengths, the hybrid effect is calculated by Equation (A4). A positive hybrid effect here is defined as a positive deviation of a certain mechanical property from the Rule of Mixture behavior.

$$
\lambda_{\text {strength }}=\frac{\sigma_{H}}{\sigma_{\text {RoM }}}-1
$$

where $\sigma_{H}$ is experimentally obtained strength of hybrid composite and $\sigma_{\mathrm{RoM}}$ is theoretically obtained value for hybrid composite using Rule of Mixture (equal to the $\sigma_{\max }^{h}$ from Equation (A2)). 
For instance, for tensile test of intraply hybrid $\mathrm{H} 3, \varepsilon_{H}=1.67 \%, \varepsilon_{L E}=1.7 \%, \sigma_{H}=1024 \mathrm{MPa}$ and $\sigma_{\mathrm{RoM}}=\sigma_{\max }^{h}=869 \mathrm{MPa}$. Hence, using te above equations,

$$
\begin{gathered}
\lambda_{\text {failure strain }}=+1.8 \% \\
\lambda_{\text {strength }}=+17.8 \%
\end{gathered}
$$

\section{References}

1. Kretsis, G. A review of the tensile, compressive, flexural and shear properties of hybrid fibre-reinforced plastics. Composites 1987, 18, 13-23. [CrossRef]

2. Swolfs, Y.; Gorbatikh, L.; Verpoest, I. Fibre hybridisation in polymer composites: A review. Compos. Part Appl. Sci. Manuf. 2014, 67, 181-200. [CrossRef]

3. Hayashi, T. On the improvement of mechanical properties of composites by hybrid composition. In Proceedings of the 8th Reinforced Plastics Group Conference, London, UK, 29 June 1977; Volume 22, p. 149.

4. Summerscales, J. The Mechanical Properties of Carbon Fibre with Glass Fibre Hybrid Reinforced Plastics. Ph.D. Thesis, University of Plymouth, Plymouth, UK, 1983.

5. Fischer, S.; Marom, G. The flexural behaviour of aramid fibre hybrid composite materials. Compos. Sci. Technol. 1987, 28, 291-314. [CrossRef]

6. Phillips, M. Composition parameters for hybrid composite materials. Composites 1981, 12, 113-116. [CrossRef]

7. Paran, S.M.R.; Abdorahimi, M.; Shekarabi, A.; Khonakdar, H.A.; Jafari, S.H.; Saeb, M.R. Modeling and analysis of nonlinear elastoplastic behavior of compatibilized polyolefin/polyester/clay nanocomposites with emphasis on interfacial interaction exploration. Compos. Sci. Technol. 2018, 154, 92-103. [CrossRef]

8. Paran, S.M.R.; Naderi, G.; Javadi, F.; Shemshadi, R.; Saeb, M.R. Experimental and Theoretical Analyses on Mechanical Properties and Stiffness of Hybrid Graphene/Graphene Oxide reinforced EPDM/NBR nanocomposites. Mater. Today Commun. 2019, 22, 100763. [CrossRef]

9. Yao, H.; Sui, X.; Zhao, Z.; Xu, Z.; Chen, L.; Deng, H.; Liu, Y.; Qian, X. Optimization of interfacial microstructure and mechanical properties of carbon fiber/epoxy composites via carbon nanotube sizing. Appl. Surf. Sci. 2015, 347, 583-590. [CrossRef]

10. Bunsell, A.; Harris, B. Hybrid carbon and glass fibre composites. Composites 1974, 5, 157-164. [CrossRef]

11. Saka, K.; Harding, J. A simple laminate theory approach to the prediction of the tensile impact strength of woven hybrid composites. Composites 1990, 21, 439-447. [CrossRef]

12. Swolfs, Y.; Verpoest, I.; Gorbatikh, L. Recent advances in fibre-hybrid composites: Materials selection, opportunities and applications. Int. Mater. Rev. 2018, 64, 181-215. [CrossRef]

13. Wisnom, M.R.; Czél, G.; Swolfs, Y.; Jalalvand, M.; Gorbatikh, L.; Verpoest, I. Hybrid effects in thin ply carbon/glass unidirectional laminates: accurate experimental determination and prediction. Compos. Part Appl. Sci. Manuf. 2016, 88, 131-139. [CrossRef]

14. Tavares, R.P.; Melro, A.R.; Bessa, M.A.; Turon, A.; Liu, W.K.; Camanho, P.P. Mechanics of hybrid polymer composites: Analytical and computational study. Comput. Mech. 2016, 57, 405-421. [CrossRef]

15. Guerrero, J.; Mayugo, J.; Costa, J.; Turon, A. A 3D Progressive Failure Model for predicting pseudo-ductility in hybrid unidirectional composite materials under fibre tensile loading. Compos. Part Appl. Sci. Manuf. 2018, 107, 579-591. [CrossRef]

16. Jalalvand, M.; Czél, G.; Wisnom, M.R. Numerical modelling of the damage modes in UD thin carbon/glass hybrid laminates. Compos. Sci. Technol. 2014, 94, 39-47. [CrossRef]

17. Mesquita, F.; Swolfs, Y.; Lomov, S.V.; Gorbatikh, L. Ply fragmentation in unidirectional hybrid composites linked to stochastic fibre behaviour: A dual-scale model. Compos. Sci. Technol. 2019, 181, 107702. [CrossRef]

18. Bunsell, A.; Gorbatikh, L.; Morton, H.; Pimenta, S.; Sinclair, I.; Spearing, M.; Swolfs, Y.; Thionnet, A. Benchmarking of strength models for unidirectional composites under longitudinal tension. Compos. Part Appl. Sci. Manuf. 2018, 111, 138-150. [CrossRef]

19. You, Y.J.; Park, Y.H.; Kim, H.Y.; Park, J.S. Hybrid effect on tensile properties of FRP rods with various material compositions. Compos. Struct. 2007, 80, 117-122. [CrossRef] 
20. Zhang, J.; Chaisombat, K.; He, S.; Wang, C.H. Hybrid composite laminates reinforced with glass/carbon woven fabrics for lightweight load bearing structures. Mater. Des. (1980-2015) 2012, 36, 75-80. [CrossRef]

21. Ren, P.; Zhang, Z.; Xie, L.; Ren, F.; Jin, Y.; Di, Y.; Fang, C. Hybrid effect on mechanical properties of M40-T300 carbon fiber reinforced Bisphenol A Dicyanate ester composites. Polym. Compos. 2010, 31, 2129-2137. [CrossRef]

22. Hwang, S.F.; Mao, C.P. Failure of delaminated interply hybrid composite plates under compression. Compos. Sci. Technol. 2001, 61, 1513-1527. [CrossRef]

23. Yerramalli, C.S.; Waas, A. Compressive behavior of hybrid composites. In Proceedings of the 44th AIAA/ASME/ASCE/AHS/ASC Structures, Structural Dynamics, and Materials Conference, Norfolk, VA, USA, 7-10 April 2003; p. 1509.

24. Manders, P.W.; Bader, M. The strength of hybrid glass/carbon fibre composites. J. Mater. Sci. 1981, 16, 2246-2256. [CrossRef]

25. Pandya, K.S.; Veerraju, C.; Naik, N. Hybrid composites made of carbon and glass woven fabrics under quasi-static loading. Mater. Des. 2011, 32, 4094-4099. [CrossRef]

26. Peijs, A.; Catsman, P.; Govaert, L.; Lemstra, P. Hybrid composites based on polyethylene and carbon fibres Part 2: influence of composition and adhesion level of polyethylene fibres on mechanical properties. Composites 1990, 21, 513-521. [CrossRef]

27. Jesthi, D.K.; Nayak, R.K. Improvement of mechanical properties of hybrid composites through interply rearrangement of glass and carbon woven fabrics for marine application. Compos. Part Eng. 2019, 168, 467-475. [CrossRef]

28. Ikbal, M.H.; Ahmed, A.; Qingtao, W.; Shuai, Z.; Wei, L. Hybrid composites made of unidirectional T600S carbon and E-glass fabrics under quasi-static loading. J. Ind. Text. 2017, 46, 1511-1535. [CrossRef]

29. Hasan, M.; Abdkader, A.; Cherif, C.; Spennato, F. Fibre hybrid composites consisting of discontinuous waste carbon fibre and continuous glass filaments developed for load-bearing structures with improved impact strength. Compos. Part Appl. Sci. Manuf. 2019, 126, 105610. [CrossRef]

30. Pandya, K.S.; Pothnis, J.R.; Ravikumar, G.; Naik, N. Ballistic impact behavior of hybrid composites. Mater. Des. 2013, 44, 128-135. [CrossRef]

31. Czél, G.; Jalalvand, M.; Wisnom, M.R. Design and characterisation of advanced pseudo-ductile unidirectional thin-ply carbon/epoxy-glass/epoxy hybrid composites. Compos. Struct. 2016, 143, 362-370. [CrossRef]

32. Fan, W.; Dang, W.; Liu, T.; Li, J.; Xue, L.; Yuan, L.; Dong, J. Fatigue behavior of the 3D orthogonal carbon/glass fibers hybrid composite under three-point bending load. Mater. Des. 2019, 183, 108112. [CrossRef]

33. Swolfs, Y. Perspective for Fibre-Hybrid Composites in Wind Energy Applications. Materials 2017, $10,1281$. [CrossRef]

34. Fiore, V.; Di Bella, G.; Valenza, A. Glass-basalt/epoxy hybrid composites for marine applications. Mater. Des. 2011, 32, 2091-2099. [CrossRef]

35. Shirvanimoghaddam, K.; Hamim, S.U.; Akbari, M.K.; Fakhrhoseini, S.M.; Khayyam, H.; Pakseresht, A.H.; Ghasali, E.; Zabet, M.; Munir, K.S.; Jia, S.; et al. Carbon fiber reinforced metal matrix composites: Fabrication processes and properties. Compos. Part Appl. Sci. Manuf. 2017, 92, 70-96. [CrossRef]

36. ASTM D3800-16. Standard Test Method for Density of High-Modulus Fibers; ASTM International Standards Organization: West Conshohocken, PA, USA, 1999.

37. ASTM D3171-99. Standard Test Methods for Constituent Content of Composite Materials; ASTM International Standards Organization: West Conshohocken, PA, USA, 1999.

38. ISO 527-4:1997. Determination of Tensile Properties_Part 4: Test Conditions for Isotropic and Orthotropic Fibre-Reinforced Plastic Composites; International Organization for Standardization: Geneva, Switzerland, 1997.

39. ISO 14126:1999. Fibre-Reinforced Plastic Composites-Determination of Compressive Properties in the In-Plane Direction; International Organization for Standardization: Geneva, Switzerland, 1999.

40. GUM-Evaluation of Measurement Data-Guide to the Expression of Uncertainty in Measurement; JCGM 100:2008; Bureau International des Poids et Mesures: Sèvres, France, 1999; p. 134.

41. Taketa, I. Analysis of Failure Mechanisms and Hybrid Effects in Carbon Fibre Reinforced Thermoplastic Composites. Ph.D. Thesis, KU Leuven, Leuven, Belgium, 2011. 
42. Ikbal, H.; Wang, Q.; Azzam, A.; Li, W. Effect of hybrid ratio and laminate geometry on compressive properties of carbon/glass hybrid composites. Fibers Polym. 2016, 17, 117-129. [CrossRef]

43. Jones, R.M. Mechanics of Composite Materials; CRC Press: Boca Raton, FL, USA, 2014.

(C) 2020 by the authors. Licensee MDPI, Basel, Switzerland. This article is an open access article distributed under the terms and conditions of the Creative Commons Attribution (CC BY) license (http://creativecommons.org/licenses/by/4.0/). 